\title{
Identification of problems when using long high voltage AC cable in transmission system I: Switching transient problems
}

Rahimi, Saeed; Wiechowski, W.; Randrup, M; Østergaard, J; Nielsen, A.H.

Published in:

2008 IEEE/PES Transmission \& Distribution Conference \& Exposition, Vols 1-3

Link to article, DOI:

10.1109/TDC.2008.4517183

Publication date:

2008

Document Version

Publisher's PDF, also known as Version of record

Link back to DTU Orbit

Citation (APA):

Rahimi, S., Wiechowski, W., Randrup, M., Østergaard, J., \& Nielsen, A. H. (2008). Identification of problems when using long high voltage AC cable in transmission system I: Switching transient problems. In 2008 IEEE/PES Transmission \& Distribution Conference \& Exposition, Vols 1-3 (pp. 567-573). IEEE. https://doi.org/10.1109/TDC.2008.4517183

\section{General rights}

Copyright and moral rights for the publications made accessible in the public portal are retained by the authors and/or other copyright owners and it is a condition of accessing publications that users recognise and abide by the legal requirements associated with these rights.

- Users may download and print one copy of any publication from the public portal for the purpose of private study or research.

- You may not further distribute the material or use it for any profit-making activity or commercial gain

- You may freely distribute the URL identifying the publication in the public portal 


\title{
Identification of Problems when Using Long High Voltage AC Cable in Transmission System I: Switching Transient Problems
}

\author{
S. Rahimi, Student Member, IEEE, W. Wiechowski, M. Randrup, J. Østergaard and A. H. Nielsen
}

\begin{abstract}
Due to political and environmental pressures from the public and government side, upgrading and building new transmission facilities are becoming more and more difficult and in some cases the expansion of overhead transmission lines are impossible. This means that underground cable technology is the proper substitution and solution which make the transmission expansion possible with minimized visual impacts on the communities.

Within European countries, Denmark was been at the forefront of replacing the transmission lines with cables. The project was supplying the power to the greater Copenhagen area in early 1990s. Recently, the Danish TSO Energinet.dk has initiated a research project for analyzing the $\mathrm{HV}$ underground cable in transmission system.

The objective of this paper and the companion paper is to address the most important problems expected in transmission system with relatively larger share of long $\mathrm{HV}$ underground cables. The end goal will be a guideline to special solutions and precautions to avoid dangerous over voltage problems and also resonance problems in a transmission network with future increased share of cables. Two major categories of problems are switching transient and resonance problems. In each category of the possible problems, first some theoretical background is provided and then the problem and countermeasures are discussed. In this paper switching transient problems are addressed and discussed. Some preliminary guidelines for modeling of the components will be given which are used especially for switching transient studies. Companion paper is dedicated to address the different types of resonance problems.
\end{abstract}

Index Terms-- Electromagnetic Transients Simulation, Switching Transients, High Voltage, Overhead Line, Underground Cable.

\section{INTRODUCTION}

$\mathrm{O}$ verhead Transmission Lines (OHL) impact on the environment due to land occupation, land value depreciation, effects on forests and territory, electromagnetic fields (EMF), radio interference, audible noise and their visual

Saeed Rahimi is Ph.D student at Centre for Electric Technology (CET) at Technical University of Denmark (DTU), Øersted.DTU, Electrovej, Bld 325, DK2800 Lyngby, Denmark (e-mail: sr@oersted.dtu.dk)

Arne Hejde Nielsen is Associate Professor at CET in Technical University of Denmark (ahn@oersted.dtu.dk). Jacob Østergaard is Professor and head of CET (joe@oersted.dtu.dk). Martin Randrup (MRA@energinet.dk) and Wojciech Wiechowski (WWI@energinet.dk) are with “Energinet.dk” Danish TSO. impact [1]. Due to political and environmental pressures from the public and government side, upgrading and building new transmission facilities are becoming more and more difficult and in some cases the expansion of overhead transmission lines are impossible. This means that underground cable technology is the proper substitution and solution which make the transmission expansion possible with minimized visual and electromagnetic field impacts on the communities. Increasing demand for electrical power by spread urban centers is also leading to the use of relatively longer cable circuit in HV level.

Development of solid insulations, the optimization of cable design and pre-moulded cable accessories contribute effectively to a lower cost of using cables in recent years. But the cost differences between cables and overheated lines are still considerable in extra high voltage (EHV) networks. This cost is inevitable for special projects in urban areas or environmentally sensitive areas, where the construction of overhead lines is rather impossible [2].

Within European countries, Denmark was been at the forefront of replacing the transmission lines with cables. The project was to supply the power to the greater Copenhagen area in early 1990s. Recently, the Danish TSO Energinet.dk has initiated a research project for analyzing the $\mathrm{HV}$ underground cable in transmission system. The scope of research is firstly to model the components of the transmission system in detail especially the $400 \mathrm{kV}$ cable and secondly to investigate the impact of the relatively larger share of the cable in transmission system [3].

The objective of this paper and its companion paper [26] is to address the second part of the research. The end goal will be a guideline to special solutions and precautions to avoid dangerous over voltage problems and also resonance problems in a transmission network with future increased share of AC cables. Different categories of possible and most probable problems are addressed and discussed in these two papers. In each category of the possible problems, first some theoretical background is provided and then the problem is discussed. Two main identifiable problem categories are as following:

a) Switching Transient over-voltages

b) Resonance and Harmonic Resonance

In this paper switching transient problems are addressed 
and discussed. After defining the problem, a mathematical representation for cable transmission system is provided and analyzed. Then some general and specific modeling guideline and requirements are provided, mostly based on IEEE PES Switching Transients Task Force guidelines [4]. These guidelines for modeling of the component will be used in next steps of the research project. Resonance and Harmonic Resonance problem are covered in companion paper [26].

\section{DESCRIPTON OF SWITCHING TRANSIENT PROBLEMS}

Switching transients are caused by the operation of breakers and switches in a power system. The switching operations itself represent three main categories:

1) Energization.

2) De-energization.

3) Re-closure.

It is important to distinguish between first and third category which are closely related. The energization phenomena include energization of system elements like transmission lines or cables, transformers, reactors, capacitor banks, etc with no trapped charge. But in case of re-closure, the line may have been left with a trapped charge after the initial breaker opening (more pronounced in cable). In such a case the transient overvoltages can reach to very high values up to $4.0 \mathrm{pu}$ [4]. De-energization includes fault clearing and load rejection, etc.

Mathematical representation and analysis of the cable transmission system is a complex task and digital simulation to be employed by using one of electromagnetic transient simulation programs available. Obviously the level of detail required in the model varies with the needed accuracy for the study.

\section{MATHEMATICAL REPRESENTATION AND ANALYSIS OF THE CABLE TRANSMISSION SYSTEM}

The method of transient analysis is based on the theory of wave propagation in multi conductor system. In switching transient over voltage problem, it is possible to ignore the presence of the soil and treating the problem as one classical wave propagation along a coaxial line, with enough accuracy for most of practical purposes.

In the theory, the transmission system is defined in terms of series-impedance matrix $\mathrm{Z}$ and a shunt-admittance matrix Y. It is shown in [5], [6] and [9], how these matrixes can be derived in terms of generalized angular frequency (to present the frequency dependent nature of parameters) and also geometry and material properties of cable. Latter provide a comprehensive formulation of formulation of impedances and admittances of single-core coaxial and pipe-type cables. As a result:

$$
\begin{aligned}
& Z(\omega)=R(\omega)+j \omega L(\omega) \\
& Y(\omega)=G(\omega)+j \omega C(\omega)
\end{aligned}
$$

where R,L,G,C are the series resistance, series inductance, shunt conductance and shunt capacitance per unit length of the cable system. These quantities are $n x n$ matrices, where $n$ is the number of (parallel) conductors of the cable system.
The variable $\omega$ shows that all quantities are calculated as function of frequency.

The electromagnetic behavior of a cable system with $n$ parallel conductor in frequency domain is described by two matrix equations [5]:

$$
\begin{aligned}
& \frac{d V(x)}{d x}=-Z(\omega) . I(x) \\
& \frac{d I(x)}{d x}=-Y(\omega) . V(x)
\end{aligned}
$$

Where $V$ and $I$ are vectors of dimension $n$ representing voltage and current at distance $x$ along the cable. It should be noted that some principal assumptions are made; such as longitudinally homogeneous cable system, mutually parallel axes of all $\mathrm{n}$ conductor, etc.

As mentioned before, all R,L,G,C can be calculated a function of $\omega$ and geometry and material properties of cable. Now the problem is calculating the voltages and currents given in (3),(4) which are implicitly function of $\omega$. For harmonic problems, i.e. case of only one specific frequency, $\omega$ is angular frequency in question, and $\mathrm{V}$ and I represent phasors. For transient problems, V and I represent the Fourier transforms of voltages and currents at values of $\omega$ lying along the path of Fourier integral necessary to convert the solution from frequency domain to time domain. It is shown in [7],[8] that for transient problems, $\omega$ need not be real and it is even better to follow a path of integration displaced below real axis (complex value of $\omega$ ). By eliminating the current vector from (3), or voltage from (4) two set of the multi conductor Telegrapher 's equation are obtained:

$$
\begin{aligned}
& \frac{d^{2} V(x)}{d x^{2}}=Z(\omega) Y(\omega) . V(x) \\
& \frac{d^{2} I(x)}{d x^{2}}=Y(\omega) Z(\omega) . I(x)
\end{aligned}
$$

which has the below set of solutions if voltage and current at distance of $x$ along cable:

$$
\begin{aligned}
& V=\exp (-x \sqrt{Z Y}) \cdot V^{+}+\exp (+x \sqrt{Z Y}) \cdot V^{-} \\
& I=Z^{-1} \sqrt{Z Y}\left[\exp (-x \sqrt{Z Y}) \cdot V^{+}-\exp (+x \sqrt{Z Y}) \cdot V^{-}\right]
\end{aligned}
$$

$V^{+}$and $V^{-}$are vectors containing $2 n$ constants of integration which are resulted from system boundary condition. For studying transient problems in time domain, above solutions are transferred back into the time domain by means of inverse Fourier transform [5], [7], [8].

$$
V(t)=\frac{1}{2 \pi} \int_{-\infty}^{+\infty} V(\omega) \exp (j \omega t) d \omega
$$

Two parameters are defined from equation (8) as following; $\mathrm{H}$ and $\mathrm{Yc}$, the propagation and characteristic admittance matrix respectively [25]: 


$$
\begin{aligned}
& H=\exp (-x \sqrt{Z Y}) \\
& Y_{c}=Z^{-1} \sqrt{Z Y}
\end{aligned}
$$

Inserting them in (7),(8) gives

$$
\begin{aligned}
& Y_{c} \cdot V_{k}-I_{k}=2 \cdot H^{T} \cdot I_{m r}=2 \cdot I_{k i} \\
& Y_{c} \cdot V_{m}-I_{m}=2 \cdot H^{T} \cdot I_{k r}=2 \cdot I_{m i}
\end{aligned}
$$

where $k$ and $m$ denote for sending end and receiving end voltage and current, respectively. By means of inverse Fourier transform matrix, (12), (13) are transferred back into the time domain:

$$
\begin{aligned}
& y_{c} * V_{k}-i_{k}=2 . h^{T} * i_{m r} \\
& y_{c} * V_{m}-i_{m}=2 . h^{T} * i_{k r}
\end{aligned}
$$

where $y_{c}$ and $h$ are the impulse responses of $Y_{c}$ and $H$ respectively, and $*$ denotes convolution. Now, the impulse responses $y_{c}$ and $h$ are needed in (14) and (15), but it is more convenient first to calculate the corresponding step responses.

The time domain step responses of $H$ and $Y_{c}$ are calculated from the frequency domain impulse responses using inverse Fourier Transform:

$$
S_{\text {step }}(t)=F^{-1}\left[\frac{1}{j \omega} S(\omega)\right]=\frac{1}{2 \pi} \int_{-\infty}^{+\infty} \frac{1}{j \omega} S(\omega) e^{j \omega t} d \omega
$$

where $\mathrm{S}$ equals either $H$ or $Y_{c}$. In order to calculate $H(\omega)$ and $Y_{c}(\omega)$, discrete version of the inverse Fourier Transform is used which means working in a very broad band of frequencies. The presence of low frequency components results requires a small frequency step length in order to avoid aliasing and presence of high frequency components requires a high upper limit in the Fourier integral. Both result in a need to the excessively large number of frequency samples and consequently computational problems. This problem has been overcome by the development of two special versions of the inverse Fourier Transform named StepFourier and SplineFourier in [25].

\section{Modeling GuIDELINES AND REQUIREMENTS}

In this section, some general and specific modeling guideline and requirements are provided. The equipment models discussed here are typically used for switching transient problems and include discussion of the extent of the system to be modeled, frequency ranges and simulation timesteps. The focus will be on cable transmission system.

\section{A. Cables Transmission System and $O H L$}

For modeling the transmission line two well known approaches are utilized; distributed parameter model and lumped parameter models. Distributed parameter models are based on the traveling time $\mathrm{t}$ and characteristic impedance $\mathrm{Zc}$ of the line and are the most efficient and accurate models compared to the lumped parameter models (pi- circuits). In fact, the lumped parameter model contains a number of cascaded short-sections of the line in order to represent and approximate the distributed nature of the physical line. This model needs more computational time and is less accurate.

Depending on the application, frequency dependency can be incorporated. When ground return mode - zero sequenceis involved i.e during a line to ground fault, a frequency dependent distributed parameter line model is necessary to give an accurate representation for a wide range of frequencies. But for the cases with mostly positive sequence conditions are involved (i.e, three-phase energization), simple distributed constant parameters models can provide sufficient accuracy [4].

For calculating the line parameters of distributed parameter model, all EMTP-type programs can be utilized. They take the geometrical and physical information (cable dimensions, height underground ground, conductor and soil resistivity, etc) as input.

An important issue is the limitation of using the lumped model (pi- circuits) for short cable lengths. The reason is that in such a case the line's traveling time $t$ is smaller than the integration step $\Delta \mathrm{t}$ of the simulation [10],[4]. However there are examples that such pi-section models have been successfully used for line energization studies without excessive loss of accuracy.

Especially for the cable studies constant parameter assumption might be too limiting. For example in a disconnect switch operation case study, a frequency dependent parameter model must be used because the frequencies may vary in a large bandwidth and the cable parameters significantly vary within that range. However it seems that for solid the dielectric cables, the constant parameter model is often adequate [4].

As a conclusion, the existing cable model in EMTP-type programs are accurate enough for short and medium range of cable length but the possibility for longer length to be examined with more detail.

\section{B. Transformers}

For switching surge transient studies it is better to use a reduced order representation with less detail compared to the very detail the transformer model used and needed for insulation studies. As general approach, a lumped parameter coupled-winding model with a sufficient number of R-L-C elements is used. This model is able to represent impedance characteristics at the terminal within the frequency range of interest. The nonlinear characteristic of the core should be taken into account and not the frequency characteristic of the core (except for the frequencies in order of 3-5 kHz) [4].

For switching surge studies, the following approaches may be used:

i ) The model directly developed from the transformer characteristic i.e, nameplate information. Standard EMTP models use this approach [11]. 
ii ) The model obtained by measured admittance matrix from frequency response of the transformer [12],[13].

iii ) A very detailed model obtained from the transformer geometry and material characteristics and then reduced to be usable in the time domain [14],[15].

Any of above models used for modeling the system containing the long cable needs to be validated. A list of practices for validation is as following:

i) Comparison of frequency response of the model (within the desired bandwidth) with the actual characteristic of transformer.

ii) Repeating above practice for all possible open and short circuit conditions on the windings.

iii) Fundamental frequency response in the form of open and short circuit impedances.

iv) Verifying turns ratio or induced winding voltages at fundamental frequency.

v) Comparison of measured and computed responses of terminal capacitance, if available.

vi) Comparison with factory tests, if available.

\section{Modeling of the Switchgear, Pre-Striking}

In switching transient studies, the switch is usually modeled as an ideal conductor (zero impedance) when it is closed, and an open circuit (infinite impedance) when open. Various options of closing time are provided by commercial transient programs, ranging from one-shot deterministic closings to multi-shot statistical or systematic closings [4].

Switches are typically categorized to two main types: Statistical switches and systematic switches. Statistical switches are the randomly closed switches whose closing times are random variables. These switches are initially open, and close at appropriate random times defined by the switch parameters, and never open again in a selected simulation. In return, a systematic switch can be used with closing time varied between a given beginning and ending time in steps which are uniformly spaced. A typical statistical over voltage study is performed by running 100 or more separate simulations of circuit breaker closings. The peak voltages for each closing operation can be recorded and maximum observed over voltage can be calculated.

Generally the time dependent statistical switches are preferable for power system circuit breakers than systematic switch. For achieving this purpose, an auxiliary (uniformly distributed statistical switch) and one normally distributed time dependent statistical switch for each phase is needed. Fig 1 shows this statistical switch for only one phase or pole of the switch.

$$
\begin{gathered}
T_{\text {Close }}^{A u x}=T_{\text {Mean }}^{A u x}+T_{\text {Random }}^{A u x} \\
T_{\text {Close }}^{A}=T_{\text {Close }}^{\text {Aux }}+T_{\text {Mean }}^{A}+T_{\text {Random }}^{A}
\end{gathered}
$$

It should be noted that (10) is for phase A and should be repeated for other phases as well. $T_{\text {Random }}^{A u x}$ is uniformly distributed and $T_{\text {Random }}^{A}$ is normally (Gaussian) distributed as shown in figure A1 in Appendix. A statistical switch is represented by mean closing times, standard deviations and the number of times that closing operations are to be performed. In practice, the probability distributions for the three breaker poles are assumed equal. Then the standard deviation for the circuit breaker poles is estimated as below:

$$
\sigma=\frac{m p s}{x}
$$

where $m p s$ is maximum pole span and $x$ is an arbitrary value left to the user. As an example, with mps equal to $5 \mathrm{~ms}$ and 5 chosen for $\mathrm{x}, \sigma=\mathrm{mps} / 5=1 \mathrm{~ms}$ give a probability of $0.012 \%$ that a closing operation be performed with a pole span greater than $5 \mathrm{~ms}$. Table I show the probability values calculated for different values of $x$ according to the properties of normal distribution function. See also Appendix.

TABLE I

PROBABILITY OF CLOSING OPERATION BEING PERFORMED WITH POLE SPAN

\begin{tabular}{c|c}
\hline $\mathrm{X}$ & Probability $(\%)$ \\
\hline 1 & 31,8 \\
\hline 2 & 4,6 \\
\hline 3 & 0.4 \\
\hline 4 & 0.16 \\
\hline 5 & 0.012 \\
\hline 6 & 0.00059 \\
\hline
\end{tabular}

Auxiliary switch has a uniform distribution and the closing time for it must be uniformly spread over exactly one cycle of the power frequency voltage. The standard deviation for auxiliary switch can be calculated based on the properties of uniform distributions, as :

$$
\sigma=\frac{1}{2 \sqrt{3} f}
$$

where $f$ is the power frequency. The mean closing time for this switch $T_{\text {Mean }}^{A u x}$ can be set in any arbitrary value not less than $T_{\text {Close }}^{A u x}$, see Fig. 1. Also for saving simulation time, it is possible to set $T_{\text {Mean }}$ to zero for all three poles.

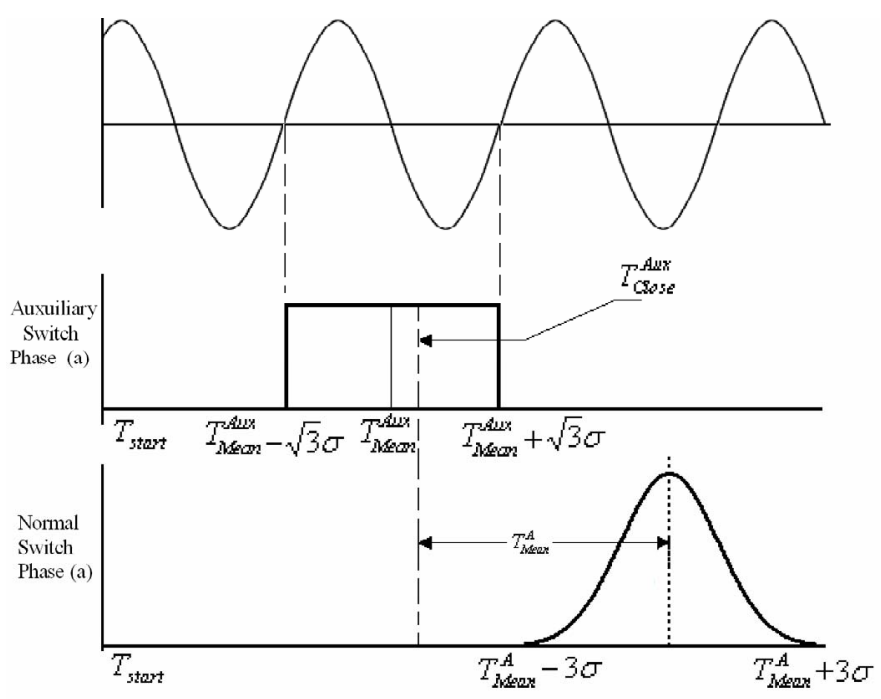

Fig. 1. Schematic of Statistical Switch operation 
In the case of using breakers with pre-insertion resistors, statistical parameters are applied for the initial closing with the resistor. It is recommended to simulate the shorting of the resistor after a fixed time, generally up to 1 cycle [4].

It is worth mentioning to introduce an important phenomenon during the operation of switches called "Breaker Pre-Strike". During energizing of a transmission lines or other equipments, traditional method of representing a circuit breaker is to assume that the contacts can close on any part of the cycle. Practically and in reality, there is a closing time between when the contacts start to close and when they finally make. Somewhere in between, an arc may strike across the contacts as they close. This is known as "pre-strike" as shown in figure 2. The vertical axis is a measure of the withstand voltage across the circuit breaker contacts in per unit. When the breaker is open, the withstand voltage of the circuit breaker will be rated voltage. The time varying value of voltage across the open contacts is depicted as an absolute function of the alternating voltage across the contacts. When the breaker contacts is close, the separation distance between the contacts reduces, then the withstand voltage reduces. Usually pre-strike occurs when the voltage across the contacts exceeds the reducing withstand voltage of the insulating medium between the contacts [16-18].

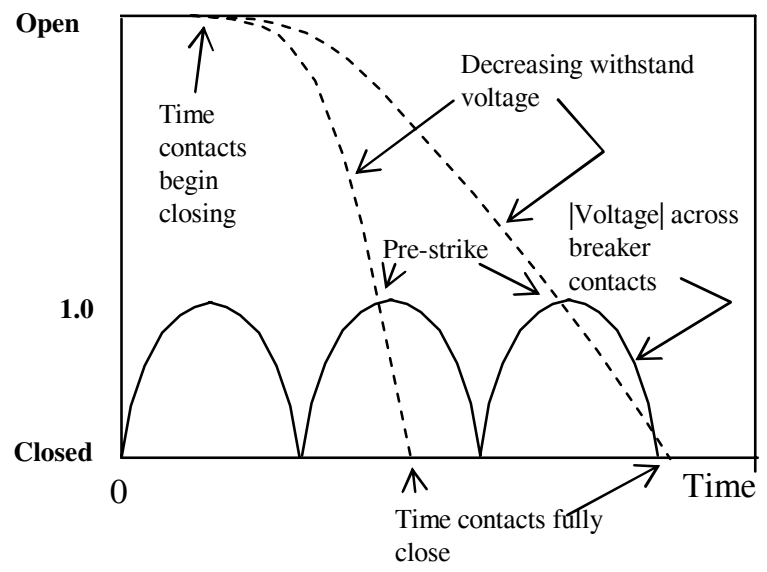

Fig. 2. Pre-strike effect in closing circuit breakers with a finite closing time [18]

Note: Speed of operation of a $230 \mathrm{kV}$, SF6 circuit breaker was found to vary with temperature, SF6 pressure, hydraulic energy and dc voltage according to a test undertaken by the Manitoba HVDC Research Centre as follows [18]:

Variations in closing speed: $8-10 \%$

Variations in opening speed: $5-6 \%$

One supplier provided the following circuit breaker closing times:

$110 \mathrm{kV} \quad 30+/-10 \mathrm{msec}$.

$220 \mathrm{kV} \quad 65+/-8 \mathrm{msec}$.

$220 \mathrm{kV} \quad 80+/-5$ msec.

$500 \mathrm{kV} \quad 80+/-5 \mathrm{msec}$.

As a result of the pre-strike, there will be a greater tendency for effective closing to occur with rising or maximum voltage across the contacts. For slow contact closing, there will even be a shadow effect where it will not be possible any effective closing to occur over a portion of the cycle.
It should be noted that some modern devices can control the closing angle of the poles to close at or near the voltage zero between the contacts (applicable to capacitor bank switching to reduce over voltages and inrush currents). It is necessary to consider the pre-strike during the modeling of breaker operation. As an example, a user-defined component has been developed to model the pre-strike effect of circuit breaker closing in PSCAD [18].

\section{Modeling of other component and Loads}

This section is dedicated to the guidelines for modeling of some important components of power system, needed for switching transient studies:

- Capacitors and Inductors

- Surge arresters

- Sources and Network Equivalents

- Loads

Capacitors and reactors are simply modeled as lumped element. For capacitor, series inductance and loss resistance are considered in some cases of switching transient studies i.e. back to back switching of capacitor banks, or faults study on capacitance bus. For more detail, damping resistance of this series inductance at natural frequency is taken into account. For reactors, the simple lumped inductor with a core saturation characteristic and series resistance is sufficient for switching transient studies. Three category of capacitance might be modeled in case of more detail:

- parallel capacitance across the reactor (for reactor opening studies, chopping of small currents)

- total capacitance (consists of bushing capacitance and equivalent winding to ground capacitance)

- terminal to ground and terminal to terminal capacitance (in case of series reactors)

Metal oxide surge arresters are represented by a nonlinear voltage versus resistance characteristic. The mathematical model proper for low frequency and slow front transient is as following. The V-I characteristic of a surge arrester has several exponential segments, where each segment can be approximated by

$$
i=p\left(\frac{v}{V_{r e f}}\right)^{q}
$$

where $q$ is the exponent, $p$ is the multiplier for that segment, and $V_{r e f}$ is an arbitrary reference voltage which normalizes the equation and prevents numerical overflow [19]. Also for fast front surges, the model of arrester can be according to the circuit shown in Fig 3. $A_{0}$ and $A_{1}$ are two time independent nonlinear resistors, $L_{0}$ and $L_{1}$ are a pair of linear inductors paralleled by a pair of linear resistors ( $R_{0}$ and $R_{1}$ ) and a capacitor $\mathrm{C}$. The V-I characteristic of $A_{1}$ is slightly less than the $8 / 20 \mu \mathrm{s}$ curve but $A_{0}$ is $20 \%$ to $30 \%$ higher. A low pass filter consists of $L_{1}$ and $R_{1}$ sees a decaying voltage across it. For considering the ground leads, a lumped 
inductance of about $1 \mu \mathrm{H}$ per meter is added in series with the model [19]. For most switching transient studies, it is recommended that wave shape dependent characteristics are not required and also the surge arrester lead lengths and separation effects can also be ignored for such studies. [20] and [21] also provide more samples of practiced models.

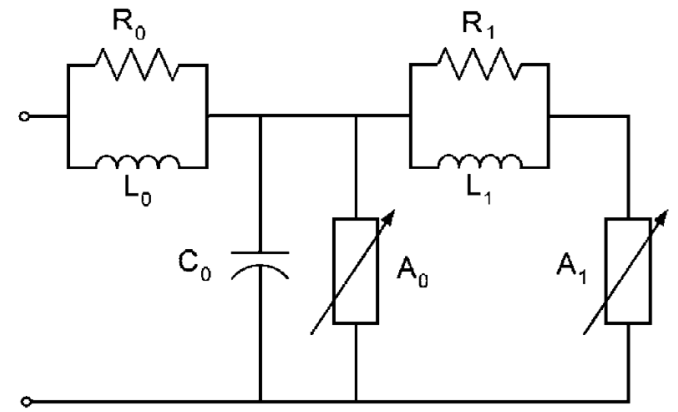

Fig. 3. MOV surge arrester model for fast front surges [19].

Sources are modeled as ideal sine-wave source in switching transient studies. Generators are modeled as voltage behind sub-transient Thevenin impedance. These are simplified model. Whenever more accuracy is needed, a more detailed model of source and power network is necessary. Three typical network equivalents are shown in Fig. 4. The $\mathrm{X} / \mathrm{R}$ ratio in first type (a) is the representative of the damping in the system (typical damping angle 75\%-85\%). Short circuit impedance in second type (b) represents the surge impedance of a connected line. In case of long cable connected to the system, this equivalent may be used. The reason is that the reflections are not of concern in the system under study and model (b) reduces connected lines to a simple equivalent surge impedance. Third model (c) is applicable when Thevenin equivalent connected system and additional transmission lines are known, though this approach may yield an incorrect steady-state solution if the equivalent impedance of the parallel connected lines is of comparable magnitude to the source impedance [4]. Three mentioned model are more accurate near fundamental frequency and some more complex equivalents are provided in [22],[23] to properly represent the frequency response characteristic.

a) Short Circuit Impedance

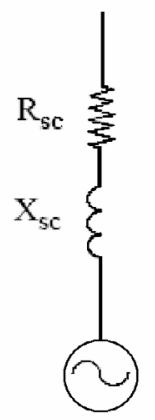

b) Surge Impedance

c) Short Circuit Impedance + Surge Impedance

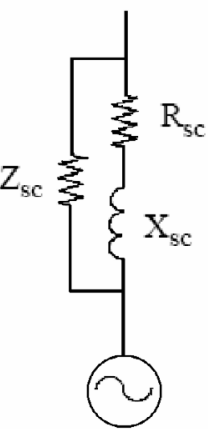

Fig. 4. Typical source and Network Equivalents used for switching transient studies [4]
Among the available load models in the literature, there is not a well developed model especially used for transient studies. Main categories of loads are as following:

- Heating and lighting loads (resistive)

- Active component of motor loads (resistive)

- Fluorescent lighting loads (inductive)

- Reactive components of motor loads (inductive)

In general, the power system load is represented by an equivalent circuit with parallel-connected resistive and inductive elements with a certain power factor. Whenever loads are lumped at a load bus, all downstream components contribute to the model of load such as cables, transformers, etc. It is recommended to use an impedance in series with the parallel R-L-C load equivalent circuit for modeling of highfrequency transient phenomena, as shown in Fig. 5(a). As typical value, the series impedance is in the range of $10-20 \%$ of the load impedance [4]. For some specific application, it might be needed to use detailed representation certain load components (e.g. induction motors) as shown in Fig. 5(b).

Actual power system with distributed loads all over the system may need different consideration for load modeling. The load impedances also may contribute in different types of resonances. This issue will need much further study which is out of scope of this paper.

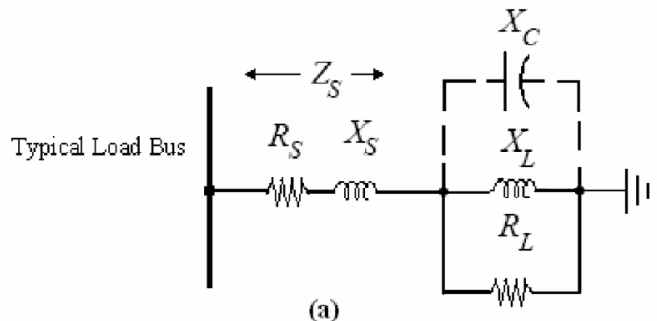

(a)

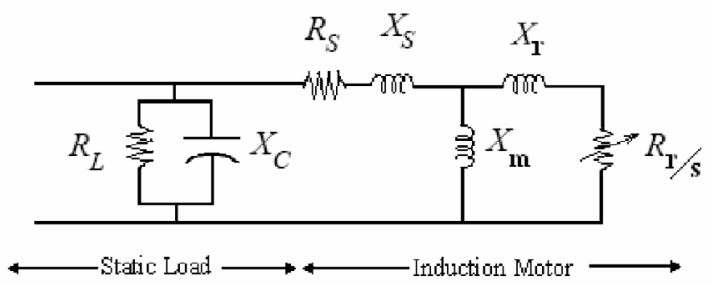

(b)

Fig. 5. Equivalent circuit representation of power system loads for simulating switching transients

(a) Typical Load Bus [4]

(b) Composite induction motor/Static Load equivalent [24]

\section{CONCLUSION}

Switching transients are one of the most important problems for operation of transmission system with large share of AC cable. The reason is laid in the difference between characteristics of cable and overhead line which makes the switching transient phenomena a more severe problem. The mathematical representation of cable transmission system is reviewed and analyzed. Some preliminary guidelines for modeling of the components are provided mostly based on IEEE PES Switching Transients Task Force guidelines. 


\section{APPENDIX}

Figure A1 shows a normal Gaussian distribution. The probability of covering area between specific multiples of standard deviation is depicted in different colors.

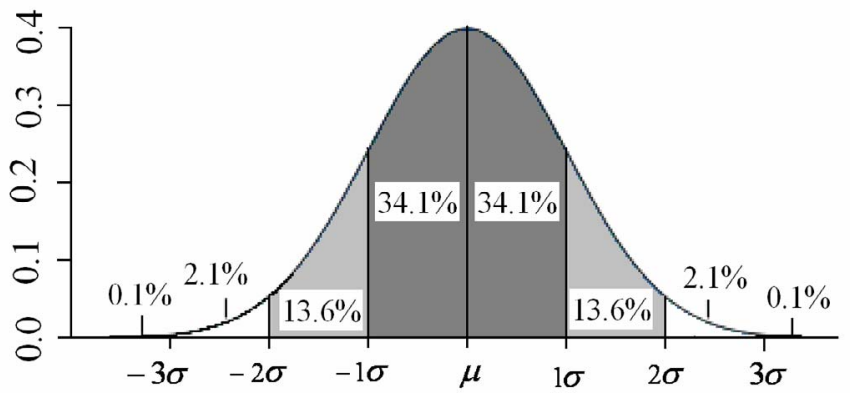

Fig. A1. Normal (Gaussian distribution) and demonstrating the probability of different areas under different multiples of standard deviation.

\section{REFERENCES:}

[1] Comparison of Overhead Lines And Underground Cables For Electricity Transmission”, Joint Working Group 21/22-01, Cigre 1996 paper No. : 21/22-01

[2] "Background Paper Undergrounding Of Electricity Lines In Europe", Commission of the European Communities, Brussels, 10 December 2003, Available [online]: ec.europa.eu/energy/electricity/publications/ doc/undergrounding.pdf

[3] "Energinet.dk finansierer forskning i $400 \mathrm{kV}$ højspændingskabler", Energinet.dk, Jun 2007, Available [ online]: http://www.energinet.dk/ $\mathrm{da} /$ menu/Nyheder/Nyhedsartikler/Energinet.dk+finansierer+forskning+i+ $400+\mathrm{kV}+\mathrm{h} \varnothing j$ spændingskabler.htm

[4] "Modeling Guidelines for Switching Transients", IEEE PES Switching Transients Task Force 15.08.09.03 (Draft Copy) Contributing Members: A.M. Gole, D.W. Durbak, E.H. Camm, M.Marz, R.C. Degeneff, R.P. O'Leary, R. Natarajan, J.A. Martinez-Velasco, Kai-Chung Lee, A. Morched, R. Shanahan, E.R. Pratico, G.C. Thomann, B. Spherling, D.A. Woodford, L. Rugeles, A. Keri....etc... Available [online]: http://www.ee.umanitoba.ca/ hvdc/faq_docs/sws97w.pdf

[5] L.M.Wedepohl, D.J Wilcox, "Transient analysis of underground powertransmission systems", Proc. IEE, Vol. 120, No. 2, pp.253-260, Feb. 1973.

[6] L.M.Wedepohl, "Application of matrix methods to the solution of travelling-wave phenomena in polyphase systems", Proc. IEE, Vol. 110 Issue.12, pp. 2200-2212, Dec. 1963.

[7] N. Mullineux, S.J; Day, J.R.Reed, "Developments in obtaining transient response using fourier transforms I. Gibbs phenomena and Fourier integrals", International Journal of Electrical Engineering Education, Vol.3, Issue.1pp. 501-506, Mar. 1965.

[8] N. Mullineux, S.J; Day, J.R.Reed, "Developments in obtaining transient response using Fourier transforms- II Use of modified Fourier transforms", International Journal of Electrical Engineering Education, Vol.4 Issue.1, pp.31-40, Apr. 1966.

[9] A. Ametani, "A General Formulation Of Impedance And Admittance of Cables", IEEE Transactions on Power Apparatus and Systems, Vol. PAS99,No. 3 , pp.902-910 May/June 1980

[10] H. W. Dommel., Electromagnetic Transients Program Reference Manual (EMTP Theory Book), Report Prepared for Bonneville Power Administration, Portland, Oregon, August 1986.

[11] V.Brandwajn, H.W. Dommel, and I.I. Dommel, "Matrix Representation of Three Phase N-Winding Transformers for Steady State and transient Studies “, IEEE Transactions on Power Apparatus and Systems, Vol: PAS-101, Issue: 6, pp. 1369-1378, June 1982

[12] A Morched, L. Marti, and J Ottevangers," A High Frequency Transformer Model for the EMTP" IEEE Trans. PWRD, Vol. 8, No. 3, pp 1615-1626, July 1993.

[13] R.J. Galarza, J.H.Chow, R.C. Degeneff, "Transformer Model Reduction Using Time and Frequency domain Sensitivity Techniques", IEEE Trans. PWRD, Vol. 10, No. 4, pp 1052-1059. April 1995.
[14] F De Leon and A. Semlyen," Reduced Order Model for Transformer Transients" IEEE Trans. PWRD, Vol. 7, No. 1, pp. 376-383, January 1992.

[15] W.J.McNutt, T.J.Blalock and R.A.Hinton,"Response of Transformer Windings to System Voltage", IEEE Trans. PAS 93 Issue. 2 pp. 457-467, March/April 1974,

[16] D.A. Woodford, L.M. Wedepohl, "Impact of Circuit Breaker Pre-Strike on Transmission Line Energization Transients," in Proc. IPST'97, International Conference on Power Systems Transients, Seattle, June 2226, 1997, pp250-253.

[17] D.A.Woodford and L.M.Wedepohl, "Transmission Line Energization with Breaker Pre-Strike", in Proc. WESCANEX'97, Conference on Communications, Power and Computing; Winnipeg, MB, Canada; May 22-23, 1997; pp. 105-108.

[18] Dennis Woodford, Course material in "Training Course and Workshop on PSCAD/EMTDC", 11 - 15 June, 2007. at Energinet.dk, .

[19] J.A Martinez, D.W. Durbak, "Parameter determination for modeling systems transients - Part V: Surge arresters “, IEEE Transactions on Power Delivery, Vol. 20, No. 3, pp. 2073 - 2078 Jul. 2005

[20] "Modeling of metal oxide surge arresters," Working Group 3.4.11 on Surge Arrester Modeling, IEEE Trans. Power Delivery, vol. PWRD-7, no. 1, p. 302, Jan. 1992.

[21] I. Kim et al., "Study of $\mathrm{ZnO}$ arrester model for steep front wave," IEEE Trans. Power Delivery, vol. PWRD-11, no. 2, p. 834, Apr. 1996.

[22] A.S. Morched and V. Brandwajn, "Transmission Network Equivalents for Electromagnetic Transients Studies", IEEE Trans. PAS, Vol. 102, No. 9, pp. 2984-2994, Sep. 1983.

[23] A.S. Morched, J.H. Ottevangers and L. Marti, "Multiport Frequency Dependent Network Equivalents for the EMTP", IEEE Trans. PWRD, Vol 8, Issue 3, pp. 1402-1412, July 1993.

[24] P. Kundur, Power System stability and control, New York: McGraw Hill, 1994., p 308.

[25] Gustavsen.B, Sletbak.J., Henriksen.T. "Calculation of electromagnetic transients in transmission cables and lines taking frequency dependent effects accurately into account", IEEE Transactions on Power Delivery, Volume 10, Issue 2, pp. 1076-1084, Apr. 1995.

[26] S. Rahimi, et al., "Identification of Problems when Using Long High Voltage AC Cable in Transmission System II: Resonance and Harmonic Resonance", Submitted to 2008 IEEE PES Transmission and Distribution Conference and Exposition, 21-24 April, 2008, Chicago, IL USA. 